\title{
ESTUDIO GENETICO MOLECULAR DE LEVADURAS DE DIVERSOS AMBIENTES
}

(Molecular genetic study of yeasts from different environments)

\author{
Carla Lozano, Salvador Barahona, Eugenio Reyes ${ }^{1}$, \\ Patricia Lodato, Patricio Retamales, Rubén León², \\ Blanca Urzúa ${ }^{2}$, Victor Cifuentes *
}

\author{
Laboratorio de Genética, \\ Depto de Cs. Ecológicas, Facultad de Ciencias, \\ Universidad de Chile. Las Palmeras 3425, Casilla 653, \\ *Email: vcifuent@uchile.cl, \\ 1: Fundación Científica y Tecnológica, ACHS, \\ 2: Departamento de Bioquímica, Facultad de \\ Odontología, Universidad de Chile.
}

Palabras claves: Levaduras, polimorfismo, cariotipo electroforético. Key words:Yeasts, polimorphism, electrophoretic karyotyping.

\section{RESUMEN}

Se describe la presencia de polimorfismo genético en levaduras nativas aisladas de diferentes ambientes, tales como: agua de mar, suelos forestales con poca intervención antrópica, suelos de viñedos, otros ambientes naturales $y$ desde pacientes con funge-mia severa. Se detectó la presencia de elementos gené-ticos extracromosómicos en cuatro cepas diferentes de levaduras. El análisis de amplificación de una region ITS utilizando partidores especificos para el ITS2 (partidores ITS3 e ITS4), permite determinar una banda de amplificación de rDNA que varia de tamaño entre 450 y $560 \mathrm{pb}$, dependiendo del género de levadura analizada. En una cepa de Cryptococcus terreus se observó la presencia de tres bandas de amplificación ITS que sugieren una organización compleja de los genes de rDNA en esa cepa. Finalmente el análisis del cariotipo electroforético de cepas ambientales y clínicas de Pichia anomala mostró un marcado poli-morfismo cromosómico en esta levadura emergente.

\section{INTRODUCCION}

Las levaduras son microorganismos fascinantes, porque sus actividades dinámicas y diversas afectan a muchas áreas de la ciencia, tecnología y medicina. Al-

\section{ABSTRACT}

The presence of genetic polymorfism is described in isolated native yeasts of different environments, such as seawater, forest soils with little human intervention, vineyards, other natural environment, and from patient with severe fungemia. The presence of extrachro-mosomal genetic elements was detected in four different yeast strains. The PCR analysis of the ITS2 region, by using specific primers (primers ITS3 and ITS4), makes it possible to determine a band of rDNA amplification having a size variation between 450 to $560 \mathrm{bp}$, depending on the kind of yeast under study. In an isolated culture of Cryptococcus terreus the presence of three ITS bands was observed, suggesting a complex organization of the rDNA genes in that strain. Finally, the analysis of the electrophoretic karyotype from environmental and clinical strains of Pichia anomala showed a marked chromosomal polymorfism in this emergent yeast.

gunas especies juegan un rol benéfico en la producción de alimentos, bebidas y fármacos, no obstante, otras son nocivas como agentes de enfermedades humanas. Ade- 
más, desde la perspectiva de la complejidad genética, su

genoma es dinámico tanto en su organización estructural

como funcional. En relación a esto, una de las caracterís-

ticas de las levaduras es su alto grado de polimorfismo

genético observado entre cepas de la misma especie. Este

polimorfismo puede ser a nivel cromosómico o de genes,

generando la variabilidad genética característica de los

hongos (Buscot et al.,1996). La organización del genoma de los hongos es un sistema complejo que debe entenderse como un todo, que en muchos casos debe estudiarse en forma parcializada, aunque su funcionamiento como tal requiere ser analizado en forma integrada. Si consideramos que el grado más básico de organización del genoma es a nivel de la secuencia de su DNA, un nivel superior de complejidad lo constituyen los cromosomas y luego la interrelación entre la estructura de dicho genoma y su función. Es en este último nivel donde se presentan una serie de interacciones que tendrán grandes efectos en el organismo. De esta manera, los cromosomas como elementos genéticos en si mismos son interesantes, debido a que su función puede ser diferente pero complementaria al análisis de los genes y sus secuencias, y en último término el arreglo que tengan sus genes constituyentes permitirá o no interacciones que pueden afectar la fisiología del gen alterando el fenotipo final del organismo.

Recientemente, ha surgido un enorme cuerpo de conocimiento de la organización genética en los organismos, que incluye la publicación de la secuencia de varios genomas completos, entre ellos el de $\boldsymbol{S}$. cerevisiae, el primero de los eucariontes (Carle \& Olson, 1984; Urzúa et al.,1997). Sin embargo, cabe destacar que hasta cerca de los ' 80 ' aún permanecían dudas respecto de si el número de cromosomas que formaban parte del genoma de esta levadura eran 16 o 17. Sólo recientemente se logró determinar que $\boldsymbol{S}$. cerevisiae tenía 16 cromosomas debido al desarrollo del análisis molecular mediante electrofo-resis de campo pulsado (Schwartz \& Cantor, 1984). Esta metodología ha permitido separar los cromosomas de muchos hongos, entre ellos los de S.cerevisiae (Carle \& Olson, 1984), Schizosaccharomyces pombe (Smith et al., 1987), Neurospora crassa (Orbach et al., 1988), Aspergillus nidulans (Brody \& Carbon, 1989), Phytophora megasperma (Howlett, 1989), Candida shehatae y Pichia stipitis (Passoth et al., 1992), Pycno-porus cinnabarinus (Cifuentes \& Martínez, 1992) y Phaffia rhodozyma (Cifuentes et al., 1997). Adicio-nalmente, la electroforesis de campo pulsado y la asignación de sondas genéticas a cromosomas específicos por hibridación, ha facilitado enormemente el análisis parasexual en aquellos hongos que carecen de fase sexual, permitiendo el establecimiento de grupos de ligamiento. Paralelamente, estos estudios han conducido al sorprendente descubrimiento que la mayoría de las especies exhiben un marcado polimorfismo cromosómico. La naturaleza exacta del polimorfismo cromosómico es desconocida y su significado biológico para el organismo no está claro. Inicialmente se propuso que éste era un medio por el cual los hongos mitospóricos (sin ciclo sexual), generan y mantienen la diversidad genética. Sin embargo, en la actualidad se sabe que dicho polimorfismo se distribuye tanto en especies asexuales como sexuales.

Estudios sobre microorganismos fúngicos aislados del medio ambiente, revelan la presencia del alto grado de polimorfismo genético, detectado a nivel del cariotipo electroforético como de regiones de DNA mediante técnicas moleculares. Similarmente, en levaduras emergentes como por ejemplo Pichia anomala se observa un marcado polimorfismo tanto en cepas aisladas desde el medio ambiente como de aislados clínicos de pacientes con fungemía. De esta manera la levadura puede existir en dos hábitat, uno como patógeno humano emergente y otro en el medio ambiente.

En este trabajo se estudia la presencia de polimorfismo genético de levaduras aisladas de diferentes hábitat que incluye aquellas que provienen del medio ambiente como aislados clínicos.

\section{MATERIALES Y METODOS}

Cepas.- Las levaduras utilizadas en este estudio corresponden a cepas aisladas de diferentes ambientes, entre las cuales se encuentran: Saccharomyces, Cryptococcus, Pichia y otras no clasificadas. Todas las cepas fueron cultivadas en un medio con extracto de levadura (YM) con agitación a $30^{\circ} \mathrm{C}$. Las cepas IM30.1, IM29.1 e IM30.18 fueron gentilmente cedidas por el Dr. Claudio Martínez (Univ. de Stgo. de Chile). Las cepas 124, H53, 259 y 189 de P. anomala fueron aisladas desde pacientes con fungémia y serán denominadas como cepas clínicas. Las cepas 671, 672,673 y 674 fueron aisladas del medio ambiente (no clínicas) y serán denominadas como cepas ambientales.

\section{Aislamiento de levaduras de muestras ambientales.-}

Muestras de suelo tomadas de diferentes ecosistemas, fueron lavadas con $500 \mu 1$ de medio de cultivo YM ( $1 \%$ glucosa; $0,3 \%$ extracto de malta; $0,3 \%$ extracto de levadura; 0,5\% de peptona) (An et al., 1989) en tubos Eppendorf. Se inoculó matraces con $10 \mathrm{ml}$ de medio YM con alícuotas de $100 \mu 1$ de la mezcla y el cultivo se incubó a $22^{\circ} \mathrm{C}$ con agitación durante $24-48$ horas. Para disminuir 
el crecimiento de bacterias que puedan estar presentes en las muestras, los medios fueron suplementados con los antibióticos ampicilina a una concentración final de 100 $\mu \mathrm{g} / \mathrm{ml}$ y tetraciclina a una concentración final de $15 \mu \mathrm{g} / \mathrm{ml}$. Posterior a la incubación, se extrajo un volumen de 100 $\mu l$ desde los matraces y se sembró en placas enriquecidas con medio de cultivo YM sólido para el crecimiento de colonias de levaduras. Para tener un stock se tomaron las colonias de levaduras desarrolladas en dichas placas y se sembraron nuevamente en YM sólido. Los cultivos fueron analizados mediante observaciones al microscopio óptico. Cuando fue necesario, levaduras aisladas de diferentes lugares fueron utilizadas en pruebas de tolerancia a metales pesados. Las levaduras fueron identificadas utilizando el kit ID32C de BioMerieux.

Extracción de DNA total de los aislados.- El DNA de los aislados fue obtenido a partir de protoplastos de las levaduras. Las cepas fueron cultivadas en $5 \mathrm{ml}$ de medio YM líquido a $22^{\circ} \mathrm{C}$ hasta saturación, luego colectadas mediante centrifugación a $7000 \mathrm{rpm}$ y resuspendidas en $500 \mu \mathrm{l}$ de $\mathrm{KCl} 0,8 \mathrm{M}$ y se agregó $100 \mu \mathrm{l}$ de glucanex a 5 $\mathrm{mg} / \mathrm{ml}$ o $35 \mu \mathrm{l}$ de zymoliasa $100 \mathrm{~T}$ a $2 \mathrm{mg} / \mathrm{ml}$. La mezcla fue incubada por 2 horas a $37^{\circ} \mathrm{C}$ centrifugando luego a 4000 rpm durante $1 \mathrm{~min}$. Los protoplastos se resuspendieron en $450 \mu \mathrm{l}$ de solución II $(50 \mathrm{mM}$ Tris- $\mathrm{HCl} \mathrm{pH} 8.0,20 \mathrm{mM}$ EDTA). Se agregó $50 \mu 1$ de SDS $10 \%$ y se incubó a $65^{\circ} \mathrm{C}$ por $30 \mathrm{~min}$. Posteriormente se agregó $20 \mu \mathrm{l}$ de proteinasa $\mathrm{K}$ a una concentración de $20 \mathrm{mg} / \mathrm{ml}$ y se incubó la mezcla a $55^{\circ} \mathrm{C}$ durante 1 hora. Se realizaron tres extracciones con fenol saturado en tampón Tris-HCl pH 7.4, dos extracciones con fenol: cloroformo:alcohol isoa-mílico $(25: 24: 1)$ y una con cloroformo: alcohol isoa-mílico (24:1), cada vez mezclando suavemente y centrifugando a $5000 \mathrm{rpm}$ por 5 min para separar las fases. El DNA se precipitó con dos volúmenes de etanol absoluto a $-20^{\circ} \mathrm{C}$, lavado con etanol al $70 \%$ y finalmente resuspendido en $50 \mu 1$ de agua bidestilada estéril. El DNA fue analizado por electroforesis en geles de agarosa al 0,7 \% en presencia de bromuro de etidio a una concentración final de $0,5 \mu \mathrm{g} / \mathrm{ml}$ (Sambrook et al., 1989).

Preparación de DNA cromosómico intacto de levaduras.- El DNA cromosómico intacto fue preparado por el método del bloque de agarosa (Schwartz \& Cantor, 1986) con algunas modificaciones (Urzúa et al., 2000; Cifuentes et al., 1997; Cifuentes \& Martínez, 1992). Células (en 50 $\mathrm{ml}$ de cultivo) de las distintas cepas, fueron colectadas por centrifugación a $4^{\circ} \mathrm{C}$ y $3.000 \mathrm{rpm}$ durante $10 \mathrm{~min}$. Luego fueron lavadas tres veces con EDTA $50 \mathrm{mM} \mathrm{pH} 7.5$, resuspendidas en $500 \mu \mathrm{l}$ de EDTA $50 \mathrm{mM}$ e incubadas por 3 a $5 \mathrm{~min}$ a $45^{\circ} \mathrm{C}$. Posteriormente, fue agregado $35 \mu \mathrm{lde}$ zymoliasa 100T a una concentración de $2 \mathrm{mg} / \mathrm{ml}$ e inme- diatamente tres volúmenes de una solución de agarosa de bajo punto de fusión al 1.3\% en EDTA 125 mM, pH 7.5. La mezcla fue agitada suavemente hasta homogeneizar la solución, depositada en moldes plásticos de $0,1 \mathrm{ml}$ e incubados a $4^{\circ} \mathrm{C}$ por 5 a $10 \mathrm{~min}$. Luego, los bloques fueron incubados en $5 \mathrm{ml}$ de tampón LET (Schwartz \& Cantor, 1986) durante $24 \mathrm{~h}$ a $37^{\circ} \mathrm{C}$. Posteriormente, los bloques fueron lavados tres veces con EDTA $50 \mathrm{mM}, \mathrm{pH} 8,0 \mathrm{e}$ incubados en $2 \mathrm{ml}$ de tampón NDS a $55^{\circ} \mathrm{C}$ por 24 horas. Finalmente, los bloques fueron lavados 3 veces con EDTA $50 \mathrm{mM}$ a temperatura ambiente y guardados en EDTA 50 $\mathrm{mM}, \mathrm{pH} 7.5$ a $4^{\circ} \mathrm{C}$ por períodos cortos, o indefinidamente a $-20^{\circ} \mathrm{C}$ en EDTA $25 \mathrm{mM}, 50 \%$ glicerol.

Electroforesis de campo pulsado.- La electroforesis de campo pulsado fue realizada en un equipo LKB usando un electrodo hexagonal. Los geles fueron preparados con agarosa al 0.9\% en tampón TBE 1M (Cifuentes et al., 1992). Para la corrida electroforética se utilizó tampón TBE 1M. La temperatura del gel y del tampón de electroforesis fue mantenida a $14^{\circ} \mathrm{C}$, con circulación constante. Los bloques de agarosa fueron ajustados en los pocillos del gel y luego sellados con agarosa al 1\% en tampón TBE $1 \mathrm{M}$. Las condiciones de electroforesis utilizó pulsos de 90 seg por 24 horas a 180 volts. Los geles fueron teñidos con bromuro de etidio $(1 \mu \mathrm{g} / \mathrm{ml})$ durante $60 \mathrm{~min}$, luego desteñidos con agua destilada durante el mismo tiempo.

\section{Amplificación de DNA mediante PCR.- La amplificación}

fue realizada utilizando como templado DNA total de cada

cepa de levadura. Se utilizó los partidores ITS3 e ITS4 para

amplificar la región inter rRNA. La amplificación se realizó

en un volumen final de $25 \mu 1$ utilizando 2 unidades de Taq

polimerasa. El programa de amplificación fue el siguiente:

3 min. a $95{ }^{\circ} \mathrm{C}, 35$ ciclos de $94{ }^{\circ} \mathrm{C}$ por $30 \mathrm{~s}, 55^{\circ} \mathrm{C}$ por 30

s, $72{ }^{\circ} \mathrm{C}$ por 3 min, seguido de una extención final de 72

${ }^{\circ} \mathrm{C}$ por $10 \mathrm{~min}$. Los productos de la amplificación fueron

analizados mediante electroforesis en geles de agarosa al

$0.7 \%$ en presencia de bromuro de etidio a una concentra-

ción final de $0.5 \mu \mathrm{g} / \mathrm{ml}$.

\section{RESULTADOS Y DISCUSION}




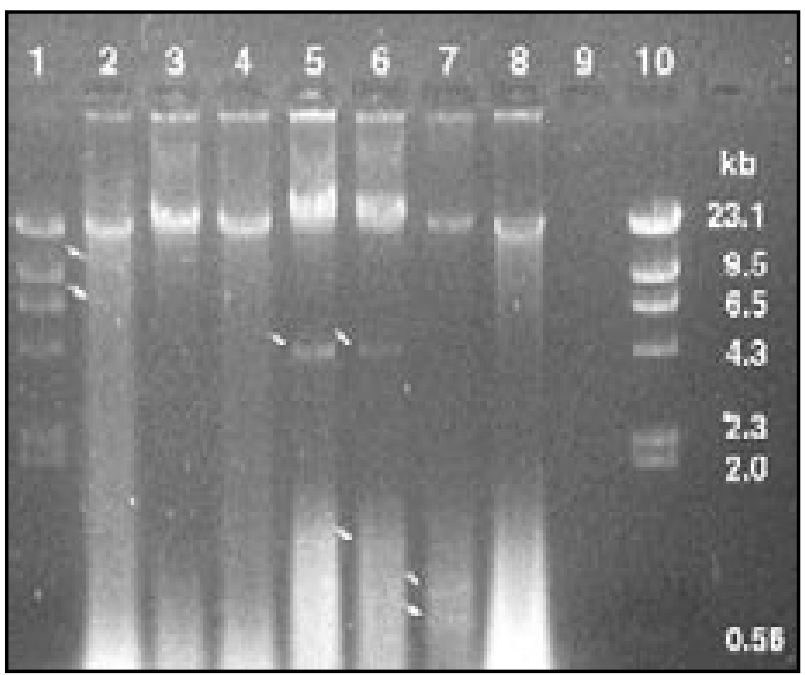

Figura 1.- Electroforesis en gel de agarosa del DNA de levaduras aisladas de diferentes localidades.

Carriles 1 y 10: DNA del bacteriófago lambda digerido con HindIII utilizado como estándar de tamaño molecular. Carril 2: cepa EG1 (levadura marina); carril 3: cepa 656 (levadura no S. cerevisiae aislada de Isla de Maipo); carril 4: cepa IM30.1; carril 5: cepa IM29.1; carril 6: cepa IM30.18; carril 7: cepa 2 (Cryptococcus terreus); carril 8: cepa 3 (C. laurentii); carril 9: control sin DNA. Carriles 3 al 6 corresponden a cepas aisladas de la localidad de Isla de Maipo. Carriles 4 al 6 ; diferentes aislados de $\boldsymbol{S}$. cerevisiae. Carriles 7 al 9 son aislados obtenidos de la localidad de Los Queules. Las flechas indican elementos genéticos extracromosómicos.

\section{Presencia de elementos genéticos extracromo- sómicos (EGEs)}

Con el objetivo de estudiar las características genéticas de levaduras aisladas de diferentes hábitat y en diferentes condiciones ambientales que relacionen cambios en la expresión génica, se procedió al aislamiento de levaduras. Algunas de éstas se aislaron a partir de diferentes muestras de suelo obtenidas de un ecosistema forestal que no presentaría aporte de cobre de origen antrópico. Además, se estudió otras levaduras colectadas en regiones vitivinícolas (Isla de Maipo), de las cuales 3 fueron identificadas como Saccharomyces cerevisiae (IM30.1, IM29.1 e IM30.18) y una no Saccharomyces (cepa 656), una levadura de origen marino y varias cepas de Pichia anomala, aisladas del medio ambiente y de pacientes con fungemia. En este último caso, se observó una clara diferencia a nivel de morfología de las colonias y resistencia a compuestos antifúngicos entre las cepas clínicas y las ambientales.

En una primera caracterización genética se realizó un análisis del DNA total de las cepas en estudio. Para ello, se procedió a la extracción del DNA a partir de protoplastos y su posterior análisis mediante electroforesis en geles de agarosa, para determinar el patrón de

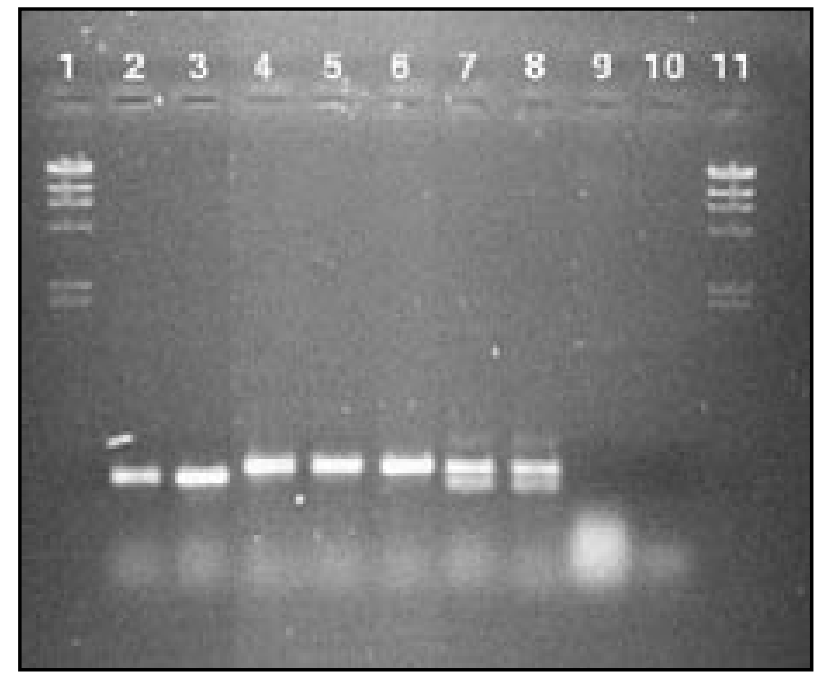

Figura 2.- Amplificación mediante PCR a partir del DNA total de las levaduras aisladas mostrado en figura 1.

Carriles 1 y 11: DNA del bacteriófago lambda digerido con HindIII; carril 2: cepa EG1; carril 3: cepa 656; carril 4: IM30.1; carril 5: IM29.1; carril 6: IM30.18; carril 7: cepa 2 (10 ng); carril 8: cepa 2 (100 ng); carril 9: cepa 3; carril 10: control sin DNA. Los partidores utilizados corresponden a ITS3 e ITS4.

migración de su DNA y detectar la presencia de elementos genéticos extracromosómicos (EGEs). Como se muestra en la figura 1, todas las cepas estudiadas presentan una banda de DNA que migra alrededor de las $23-50 \mathrm{~kb}$ y que corresponde a DNA cromosómico. Sin embargo, algunas cepas de levaduras son portadoras de elementos genéticos extracromosómicos como se indica mediante flechas en la figura 1. Así, la cepa marina EG1 presenta dos bandas tenues de aproximadamente 11 y $6.7 \mathrm{~kb}$ respectivamente (figura 1, carril 2). Adicionalmente, las cepas IM29.1 e IM30.18 aisladas de la localidad de Isla de Maipo y pertenecientes a la especie $\boldsymbol{S}$. cerevisiae, muestran claramente la presencia de EGEs (figura 1, carriles 5 y 6 ), indicado por las flechas. El análisis molecular indicó que ambas cepas compartieron una banda de $4.2 \mathrm{~kb}$, pero se diferenciaron en que la cepa IM30.18 presentó una banda adicional de aproximadamente $1.0 \mathrm{~kb}$. Por otra parte, los resultados de la electroforesis, muestran que otras levaduras aisladas de la localidad de "Los Queules", que se caracterizaron en el laboratorio por ser tolerantes a altas concentraciones de cobre en el medio de cultivo, presentaron la característica banda de DNA de sobre $23 \mathrm{~kb}$. Sin embargo, la cepa 2, identificada como Cryptococcus terreus mostró la presencia de dos EGEs correspondientes a dos bandas de $0.75 \mathrm{y}$ $0.56 \mathrm{~kb}$ respectivamente y que se indica por flechas en el carril 7 de la figura 1. La otra levadura de "Los Queules", la cepa 3 fue identificada como Cryptococcus laurentii y no presenta EGEs.

Cabe destacar que en la mayoría de los hongos estudiados es posible detectar la presencia de ácidos nucleicos extracromosómicos. En muchos casos, se trata 


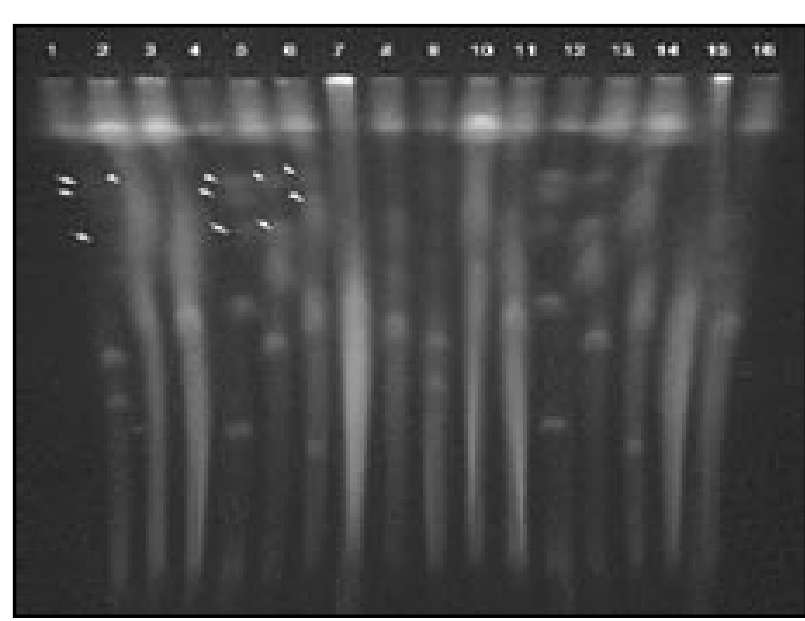

Figura 3: Electroforesis de campo pulsado de DNA cromosómico intacto de cepas de Pichia anomala.

Carriles 1 y 9: cepa 124; carriles 2 y 10: cepa H53; carriles 3 y 11: cepa 259; carriles 4 y 12: cepa 189 ; carriles 5 y 13: cepa 671; carriles 6 y 14: cepa 672; carriles 7 y 15: cepa 674; carriles 8 y 16: cepa 673. las condiciones de electroforesis fueron pulsos de 90 segundos a 180 volts durante $24 \mathrm{hrs}$ en un gel de agarosa al $0.9 \%$ en TBE $1 \mathrm{M}$.

de moléculas de RNA de doble hebra (dsRNA) (Buck, 1986; Koltin \& Leibowitz, 1988) y en otros menos frecuente corresponden a moléculas de DNA de doble hebra (dsDNA) (Gunge, 1983). Casi en la totalidad de los casos descritos los dsRNAs se encuentran encapsidados en partículas tipo virus (VLPs) citoplasmáticas, sin embargo, sólo se ha reportado un caso de micovirus de dsDNA en el hongo acuático Rhizidiomyces (Dawe \& Kuhn, 1983). También cabe la posibilidad de fraccio-namiento genético por manipulación durante la extracción del DNA y es necesario observar el patrón de migración no sólo en geles de agarosa sino que en otros (PAGE), con patrones de pesos moleculares estándares conocidos para el material genético extracromosómico. En las especies mejor estudiadas, se ha demostrado la existencia de fenotipos característicos asociados a estos elementos genéticos. Tanto en algunas levaduras que poseen dsRNAs, como S.cerevisiae (Bruenn, 1986), Ustilago maydis (Koltin, 1986) o P.rhodozyma (Castillo et al., 1994), así como en otras que contienen dsDNAs lineales, Kluyveromyces lactis (Gunge, 1983), P.rhodozyma (Martínez et al., 1994) y Pichia acaciae (Worsham \& Bolen, 1990), se ha descrito un sistema killer asociado a estos elementos. En estos casos, las levaduras killer secretan una proteína tóxica que destruye a células sensibles de la misma especie, siendo las cepas killer inmunes a su propia toxina. En otras especies de hongos filamentosos que contienen dsRNAs, como Rhizoctonia solani, Endothia parasitica y Bipolaris victoriae (Ghabrial, 1986), los fenotipos conferidos por estas moléculas son hipovirulentas, de lento crecimiento y sin o escasa esporulación, respectivamente.

\section{Caracterización mediante amplificación de ITS por PCR.}

Como fuera descrito, los ITS (internal transcriber spacer) del rDNA son un buen marcador para estudiar el polimorfismo que se relacionan con la variaciones genéticas entre e intraespecies (Buscot et al., 1996). Como una caracterización de las cepas nativas aisladas de las tres localidades descritas, se realizó un análisis amplifi-cando mediante PCR, la región ITS entre el rDNA de 5.8S y 28S. Para ello se utilizó los partidores ITS3 e ITS4 que amplifican un fragmento de DNA de aproximadamente $450 \mathrm{pb}$, dependiendo del género estudiado. La figura 2 muestra los resultados de la amplificación de la región ITS de la cepa marina EG1, las cepas aisladas de suelo de Isla de Maipo 656, IM30.1, IM29.1 e IM30.18 y de Los Queules cepa 2 y cepa 3 . Como se muestra en la figura 2, el tamaño del producto de amplificación del DNA ITS cae dentro de un rango de tamaño de entre 450 a 500 pb. La cepa marina EG1 origina un producto de amplificación ligeramente mayor (aprox. 20 pb) que la cepa 656 (no Saccharomyces de Isla de Maipo). Adicionalmente, las tres cepas de $\boldsymbol{S}$. cerevisiae de Isla de Maipo, IM30.1, IM29.1 e IM30.18, presentan un patrón único de fragmento cuyo tamaño molecular aproximado es $485 \mathrm{pb}$. Como se esperaba, no se observan diferencias de tamaño de la región ITS2 entre estas cepas debido a que pertenecen a la misma especie. Sin embargo, de los resultados mostrados en la figura 1, estos tres aislados corresponden a cepas diferentes ya que una (IM30.1) carece de EGEs y las otras dos presentan uno (IM29.1) y dos (IM30.18) EGEs respectivamente. Para determinar el polimorfismo entre estas cepas, sería necesario hacer un estudio a nivel de secuencia de los productos de amplificación. Por otra parte, el análisis de amplificación mediante PCR con los partidores ITS3 e ITS4 de las cepas de Los Queules, muestró que la cepa 2 de C.terreus, presenta una banda principal de un tamaño aproximado de $475 \mathrm{pb}$ y dos bandas tenues de 450 y 560 pb respec-tivamente (ver Figura 2 carriles 7 y 8). Este resultado sugiere que en esta cepa los genes de rDNA, podrían estar organizados de una manera compleja, producto de algún evento de recombinación intracromosómica que involucran directamente al rDNA. En la cepa 3 de $\boldsymbol{C}$. laurentii, no se observa producto de amplificación. Este resultado podría deberse a que los partidores ITS3 e ITS4 no reconocen una secuencia en el DNA molde o bien y lo más probable, que la reacción de PCR requiere de otras condiciones para amplificar o simplemente hubo un error en la reacción. Como fue indicado anteriormente, para lograr un dato más informativo, será necesario profundizar el análisis a nivel de la secuencia nucleotídica de los fragmentos ITS2 amplificados, determinar las diferencias 
a nivel de sustituciones de bases y su comparación con las secuencias publicadas en las bases de datos como GeneBank, mediante análisis SSCP. Un estudio preliminar con la secuencia nucleotídica del la cepa 2 y 3 comparada a las publicadas en GenBank, confirma la identificación de estas cepas como Criptococcus terreus y C.laurentii respectivamente (dato no mostrado).

\section{Análisis del polimorfismo cromosómico de Pichia anomala.}

Como fue indicado anteriormente, el estudio de diferentes cepas de P.anomala, aisladas desde el medio ambiente y de pacientes con fungémia a nivel morfológico y fisiológico, mostraron diferencias entre las cepas según su origen. Así, se observó que había cambios en la morfología de las colonias, velocidad de crecimiento y resistencia a agentes antifúngicos (nistatina, ketoconazol, anfotericina B) entre las cepas ambientales y las clínicas (datos no mostrados) (Reyes 1999). Para determinar la presencia de polimorfismo en las cepas de P.anomala se elaboró el cariotipo electroforético de cepas clínicas y ambientales de P.anomala. Para ello se preparó DNA cromosómico intacto de cuatro cepas clínicas (cepas: 124, H53, 259

estudios morfológicos y fisiológicos entregan una herramienta poderosa para estudiar la organización genómica estructural y funcional de estos microorganismos.

\section{AGRADECIMIENTOS}

Este trabajo ha sido financiado por la Fundación Científica y Tecnológica de la ACHS. El Depto. de Invest. y Desarrollo (D.I.D) de la Univ. de Chile. EL DAAD de Alemania a través de una beca doctoral a la Srta. Patricia Lodato y la Fundación María Ghilardi Venegas mediante una Beca doctoral al Sr. Patricio Retamales.

An, G.H.; Schuman, D.B. \& Johnson, E.A. (1989). Isolation of $X$. dendror-

hous mutants with increased astaxanthin content. Appl. Environ. Microbiol. 55:116-124

Bruenn, J. (1986). The killer systems of Saccharomyces cerevisiae and other yeasts. In Fungal Virology, K.W. Buck (Ed.). CRC Press, Boca Raton, Florida, pp. 85-108

Brody, H. \& Carbon, J. (1989). Electrophoretic karyotype of Aspergillus nidulans. Proc Natl Acad Sci 86:6260-6263

Buck, K.W. (1986). Fungal Virology. K.W. Buck (Ed.) CRC Press, Boca Raton, Florida.

Buscot,F.; Wipf, D.; Di Battista,C.; Munch, J.C.; Botton,B.; Martin, F. (1996) . DNA polimorfism in morels.I. PCR/RFLP analysis of the ribosomal DNA spacers and microsatellite-primed PCR. Mycol. Res. 100: $63-71$

Carle, G. \& Olson, M.V. (1984). Separation of chromosomal DNA molecules from yeast by orthogonal-field-alternation gel electrophoresis. Nucleic Acids Res. 12:5647-5664 y 189) y cuatro cepas ambientales (cepas: 671, 672, 673 y 674). Como se muestra en la figura 3 , claramente se observa un marcado polimorfismo cromo-sómico en las cepas de esta especie de levadura emergente. En las cepas clínicas 124 y 189 se aprecia que comparten al menos tres bandas cromosómicas (carriles 1 y 4 en figura 3). Similarmente, al menos 5 cepas, tres clínicas y dos ambientales comparten al menos una banda cromosómica como indica la flecha superior en las cepas clínicas 124, H53 y 189 y las cepas ambientales 671 y 672 (Figura 3, carriles 1, 2, 4, 5 y 6). Adicionalmente, se observa que las cepas 124,189 y 671 comparten una banda cromosómica como se indica con la flecha inferior en la figura 3 (Figura 3 carriles 1, 4 y 5). El polimorfismo cromosómico es un evento frecuente en hongos en general y particularmente en levaduras. Si este polimorfismo esta o no relacionado con los cambios fenotípicos observados en estas cepas de acuerdo a su origen clínico o ambiental, deberá ser mayormente investigado. Como se puede observar a partir de los datos presentados, las técnicas moleculares permiten deter-minar la gran variabilidad genética existente en los hongos, específicamente en levaduras, que junto con

Castillo, A. \& Cifuentes, V. (1994). Presence of double stranded RNA and virus-like particles in Phaffia rhodozyma. Current Genet. 26: 364368

Cifuentes,V. \& Martínez,C. (1992). Análisis del genoma de P. cinna-barinus mediante electroforesis de campo pulsado. Bol. Micol.7: 31-37

Cifuentes, V.; Hermosilla, G.; Martínez, C.; León, R.; Pincheira, G.; Jiménez, A. (1997). Genetics and electrophoretic karyotyping of wildtype and astaxanthin mutant strains of Phaffia rhodozyma. Antonie van Leeuwenhoek 72:111-117

Dawe, V.H. \& Kuhn, C.W. (1983). Isolation and characterization of a double-stranded DNA mycovirus infecting the acuatic fungus, Rhizidiomyces. Virology 130: 21-28

Ghabrial, S.A. (1986). A transmissible disease of Helminthosporium victoriae- Evidence for a viral etiology. In Fungal Virology, K.W. Buck (Ed.). CRC Press, Boca Raton, Florida, pp. 163-176

Gunge, N. (1983). Yeast DNA plasmids. Annu. Rev. Microbiol. 37: 253-276

Howlett, B. (1989). An electrophoretic karyotype for Phytophtora megasperma. Experimental Mycology 13: 199-202

Koltin, Y. (1986). The killer systems of Ustilago maydis. In Fungal Virology, K.W. Buck (Ed.). CRC Press, Boca Raton, Florida, pp. 109-141

Koltin, Y. \& Leibowitz, M. (1988). Viruses of Fungi and Simple Eukaryotes. Marcel Dekker, Inc. New York.

Martínez, C.; Hermosilla, G.; León, R.; Urzúa, B. ; Cifuentes, V. (1994). Presencia de plásmidos de DNA de doble hebra en Phaffia rhodozyma. Bol. Micol. 9: 25-30

Orbach, M.; Vollrath, D.; Davis, R. \& Yanofsky, C. (1988). An electrophoretic karyotype of Neurospora crassa. Mol. Cell. Biol. 8: 1469-1473 